\title{
Usefulness of Telemetric Blood Pressure Monitoring in Hypertensive Patients with Chronic Kidney Diseases
}

Burnier $\mathbf{M}^{1 *}$, Bock $A^{2}$, Halabi $\mathbf{G}^{3}$, Gasser $\mathrm{UE}^{4}$, Pechère Bertschi $\mathrm{A}^{5}$, Ambühl $\mathrm{P}^{6}$, Forster $\mathrm{C}^{6}$, Gabutti $\mathrm{L}^{6}$, Giovannini $\mathbf{M}^{6}$, Hess $\mathrm{B}^{6}$ Meier $\mathbf{P}^{6}$, Mohaupt $\mathbf{M}^{6}$, Pfammatter $\mathbf{R}^{6}$, Schönholzer $\mathbf{C}^{6}$, Schwarz $\mathbf{A}^{6}$, Steiger $\mathbf{J}^{6}$, Wagner $\mathbf{G}^{6}$ and Würzner $\mathbf{G}^{6}$

${ }^{1}$ Department of Nephrology and Hypertension, CHUV, Lausanne, Switzerland

${ }^{2}$ Division of Nephrology, Kantonsspital Aarau, Switzerland

${ }^{3}$ Hospital Northern Vaud, Yverdon, Switzerland

${ }^{4}$ ClinResearch Ltd, Aesch, Switzerland

${ }^{5}$ University Hospitals of Geneva, Geneva, Switzerland

${ }^{6}$ The Swiss Telemetry-Nephro Group, Switzerland

\begin{abstract}
Introduction: The quality of Blood Pressure (BP) control remains poor among patients with Chronic Kidney Diseases (CKD). It is therefore crucial to develop therapeutic strategies enabling improvement in BP control in order to retard the progression of the underlying renal diseases. The cornerstones of therapy include the use of effective and well tolerated drugs and a good drug adherence. In this pilot study conducted in ambulant routine care we evaluated the potential clinical benefits of implementing a Telemonitoring System (TMS) in parallel to an anticipated change of treatment in hypertensive CKD patients with uncontrolled hypertension and/or adverse reactions due to the current antihypertensive treatment.
\end{abstract}

Methods: This is an observational study conducted by 13 Swiss nephrologists in patients with CKD stage III-IV and a $\mathrm{BP}>130 / 80 \mathrm{mmHg}$ under treatment with an antihypertensive drug. A validated, automated TMS for home BP and Heart Rate (HR) monitoring and an electronic scale to measure Body Weight (BW) and a modem to transfer the measured parameters to a central database were provided to each patient. The protocol included a run-in phase and a drug titration phase of 1 month each and a 2 month maintenance phase. During the titration phase, the calcium antagonist lercanidipine could be introduced and up titrated in case of uncontrolled BP.

Results: The use of a TMS in conjunction with the introduction of lercanidipine resulted in a significant reduction of office systolic and diastolic BP of respectively $-10 \pm 21 \mathrm{mmHg}(p=0.028)$ and $-5.0 \pm 11 \mathrm{mmHg}(p=0.049)$. Home BP revealed a parallel significant reduction of $-3 \pm 1.4 \mathrm{mmHg}$ systolic $(p=0.043)$ and $-3 \pm 1.2 \mathrm{mmHg}(p=0.021)$ diastolic, respectively. The fall in BP was associated with a slight but significant increase in serum creatinine and decrease in Estimated Glomerular Filtration Rate (eGFR)

Conclusion: The results of this observational pilot study suggest that a telemonitoring system enabling to follow home BP may be useful to improve BP control in hypertensive patients with CKD. However, a prospective randomized control study would be needed to assess the real added benefits of this strategy. Administration of lercanidipine in CKD patients was effective and well tolerated.

Keywords: Hypertension; Telemedicine; Chronic kidney diseases (CKD); Home blood pressure; Calcium antagonists

\section{Introduction}

Hypertension is one of the major risk factor for the progression of Chronic Kidney Disease (CKD) whatever the origin of the renal disease [1]. Although many effective antihypertensive drugs have been developed, target $\mathrm{BP}$ according to international guidelines $(\mathrm{BP}<130 / 80$ $\mathrm{mmHg}$ ) are reached only in a very small proportion of hypertensive patients with diabetes or non-diabetic nephropathies [2,3]. There is therefore a strong need to improve the quality of BP control overall, and particularly in CKD patients in order to reduce the persisting high cardiovascular risk of these patients' population and to retard the progression of their renal disease [4].

Several factors have been identified which may be important to improve $\mathrm{BP}$ control in $\mathrm{CKD}$ as well as in the general hypertensive population. These include fighting against the medical inertia, monitoring BP outside the physician's office and supporting long term adherence to therapy [5]. These three factors could be markedly improved by the use of a Telemonitoring System (TMS) with a guidance for the patients on how and when perform ambulant BP measurements that provides regular medical information to physicians [6-8]. In addition, BP control in hypertensive patients with renal insufficiency requires the use of effective antihypertensive treatments with favorable renal properties and excellent tolerability including a low incidence of edema. Indeed, studies have demonstrated that the likelihood that a patient remains under the prescribed therapy depends on the tolerability profile of the drugs and on their ability to lower blood pressure effectively and rapidly [9]. In this respect, Calcium Channel Blockers (CCBs) are recognized as very effective antihypertensive therapies, also for patients with renal insufficiency, and trials have demonstrated their ability to reduce cardiovascular events [10-13].

However, the efficacy of CCBs is often limited by the occurrence of peripheral edema which can affect up to $30 \%$ of patients when the CCB is given alone or about $20 \%$ when combined with a blocker of the ReninAngiotensin System (RAS) [10-13]. Lercanidipine is a long acting DHP

*Corresponding author: M. Burnier, Department of Nephrology and Hypertension, Rue du Bugnon 17, CHUV, 1011 Lausanne, Switzerland, Tel: +41213141154; Fax: +41213141139; E-mail: michel.burnier@chuv.ch

Received May 09, 2012; Accepted June 26, 2012; Published June 29, 2012

Citation: Burnier M, Bock A, Halabi G, Gasser UE, Bertschi PA, et al. (2012) Usefulness of Telemetric Blood Pressure Monitoring in Hypertensive Patients with Chronic Kidney Diseases. J Nephrol Therapeut 2:122. doi:10.4172/21610959.1000122

Copyright: $\odot 2012$ Burnier M, et al. This is an open-access article distributed under the terms of the Creative Commons Attribution License, which permits unrestricted use, distribution, and reproduction in any medium, provided the original author and source are credited. 
$\mathrm{CCB}$ of the third generation which may be of interest for patients with $\mathrm{CKD}$ as it demonstrated postglomerular vasodilatory capacities in the hypertensive animal $[14,15]$. In patients with CKD and/or proteinuria already treated with a blocker of the RAS, the addition of Lercanidipine was found to be effective in lowering BP and proteinuria with a low incidence of peripheral edema [16].

The objective of this pilot study conducted by a group of Swiss nephrologists was to evaluate the clinical benefits of implementing a $\mathrm{BP}$ and body weight TMS at the patient's home to improve BP control and monitor the occurrence of edema in patients with chronic kidney diseases in conjunction with the administration of lercanidipine.

\section{Patients and Methods}

This was a non-interventional, observational, pilot study conducted by 13 Swiss nephrologists in patients with CKD and an uncontrolled BP. The protocol was approved by the Institutional Review Board of Basel.

Male and female hypertensive patients with CKD stage III or IV according to the MDRD formula having not achieved a normalized $\mathrm{BP}$ according to European guidelines $(<130 / 80 \mathrm{mmHg})$ [3] or experiencing adverse drug reactions to antihypertensive treatment were enrolled in the study. The study outline is presented in figure 1. Once the telemonitoring was installed at the patient's home, the study started with a 1 month run-in phase to evaluate the reliability of the system and to obtain the baseline home BP measurements on their regular treatment schedule. No change in therapy was planned during this phase. At visit 2, home BP data were discussed with the patients, confronted to the office BP and Lercanidipine (10-20 mg) could be introduced if BP remained above targets $(>130 / 80 \mathrm{mmHg})$. The dose of lercanidipine could be adapted according to home BP during the next month (titration phase). If required, doses of other antihypertensive drugs when administered in combination with lercanidipine could be adapted as well during this treatment phase. Thereafter, patients were monitored for another 2 month period (maintenance phase). Office BP and a physical examination were performed at each visit.

\section{Telemonitoring}

For the monitoring of home BP, a validated, automated Telemonitoring System (TMS; Stabil-O-Graph; Stolberg, Germany) [17] was used which enables to monitor BP and heart rate and is also combined with a scale to measure Body Weight (BW). Monitoring of BW was done in order to investigate the development of subclinical edema. The data collected were transferred via a modem to a central database. Patients were instructed to measure their BP and HR twice a day (morning and evening) and the BW once daily on at least 5 days of the week. Participating nephrologists had password protected access to the data of their patients. Patients were instructed how to use the TMS and to transfer the generated data to the central data base using the modem at baseline visit (V1). The TMS featured setting alerts for exceeding maximum and/or increased mean values as well as for noncompliance on agreed measuring intervals.

Anonymous clinical data were collected during routine care visits and entered by the nephrologists in an Electronic Data Capture (EDC) system and data generated by patients at home using the TMS were transferred by a modem to the database. Routine data quality checks were performed and clinical data were analyzed using descriptive statistics (analysis of variance for repeated measurements and student $t$-tests). Clinical efficacy and safety were evaluated in all patients who had a baseline and at least one follow up documentation.

\section{Results}

A total of 34 patients were enrolled and started using the TMS. 27 patients agreed to accomplish a modification of the treatment regimen and to continue using the TMS in parallel. Out of the 27 included patients, two patients decided to stop using the TMS and two patients dropped out during the follow up periods. Thus, 23 patients ( $85 \%$ of the included patients) completed the entire program.

\section{Baseline characteristics of patients}

The characteristics of the patients are shown in Table 1. Median age was 62 years (range: 26 to 83 years) and median body weight was $80 \mathrm{~kg}$ (range: 52 to $123 \mathrm{~kg}$ ). The median duration of CKD was 7 years, $37 \%$ of patients had type 2 diabetes. Moderate proteinuria $(<1 \mathrm{~g} / 24 \mathrm{~h})$ was present in $30 \%$ and severe proteinuria ( $>1 \mathrm{~g} / 24 \mathrm{~h}$ ) in $37 \%$ of patients. One third of patients suffered from a co-morbidity such as obesity, cardiac problems, cancer, rheumatic disease or psoriasis. The frequencies of antihypertensive treatments administered at start of investigation are summarized by substance classes in Table 1. All patients were on multiple drug therapies at baseline. Baseline laboratory values and renal parameters are shown in Table 1 and Table 2.

\section{Treatments}

Individual antihypertensive treatment regimens were changed after the run-in period at V2, either due to insufficient efficacy or due to adverse events on previous treatments in $80 \%$ and $20 \%$ of the included patients, respectively. Figure 2 shows the proportion of patients

\begin{tabular}{|ccccccc|}
\hline $\begin{array}{c}\text { Baseline } \\
\text { Visit 1 }\end{array}$ & Run-in & $\begin{array}{c}\text { Treatment } \\
\text { change } \\
\text { Visit 2 }\end{array}$ & $\begin{array}{c}\text { Titration } \\
\text { period }\end{array}$ & $\begin{array}{c}\text { Follow } \\
\text { up visit } \\
\text { FU1 }\end{array}$ & Maintenance period & $\begin{array}{c}\text { Follow } \\
\text { up visit } \\
\text { FU2 }\end{array}$ \\
\hline BP in clinic & Telemetry & $\begin{array}{c}\text { BP in } \\
\text { clinic }\end{array}$ & Telemetry & $\begin{array}{c}\text { BP in } \\
\text { clinic }\end{array}$ & Telemetry & $\begin{array}{c}\text { BP in } \\
\text { clinic }\end{array}$ \\
\hline
\end{tabular}

Figure 1: Schematic representation of the study protocol. 
Citation: Burnier M, Bock A, Halabi G, Gasser UE, Bertschi PA, et al. (2012) Usefulness of Telemetric Blood Pressure Monitoring in Hypertensive Patients with Chronic Kidney Diseases. J Nephrol Therapeut 2:122. doi:10.4172/2161-0959.1000122

Page 3 of 6

\begin{tabular}{|l|l|}
\hline Gender F/M & $5 / 22$ \\
\hline Age $($ years $)$ & $58.9(14.7)$ \\
\hline Weight $(\mathrm{kg})$ & $83.4(15.4)$ \\
\hline SBP $(\mathrm{mmHg})$ & $146.9(16.3)$ \\
\hline DBP $(\mathrm{mmHg})$ & $86.9(12.9)$ \\
\hline HR $($ beats $/ \mathrm{min})$ & $71.5(14.4)$ \\
\hline Serum creatinine $(\mu \mathrm{mol} / \mathrm{l})$ & $202(95)$ \\
\hline eGFR $\left(\mathrm{ml} / \mathrm{min} / 1.73 \mathrm{~m}^{2}\right)$ & $36(18)$ \\
\hline Diabetics & $10(37 \%)$ \\
\hline Proteinuria & \\
\hline moderate $(<1 \mathrm{~g} / \mathrm{d})$ & $8(30 \%)$ \\
\hline severe $(>1 \mathrm{~g} / \mathrm{d})$ & $10(37 \%)$ \\
\hline Other co-morbidities & $10(37 \%)$ \\
\hline $\begin{array}{l}\text { Administered antihypertensive drugs (either monotherapy or combination } \\
\text { therapy) }\end{array}$ & \\
\hline ACE Inhibitor & $10(37 \%)$ \\
\hline Angiotensin-Il-antagonist & $17(63 \%)$ \\
\hline Betablocker & $14(52 \%)$ \\
\hline Calcium antagonist & $14(52 \%)$ \\
\hline Diuretics & $19(70 \%)$ \\
\hline Renin Inhibitor & $3(11 \%)$ \\
\hline
\end{tabular}

Values are means (SD) or actual numbers (\%).

NOTE: UNITS SHOULD BE HIGHLIGHTED

Table 1: Clinical characteristics of the included patients.

treated with each of the 6 antihypertensive classes (CCB, Angiotensin Converting Enzyme (ACE) inhibitor, beta-blocker, ARB, and diuretics). Lercanidipine was introduced as "add on" or "substitution" in $63 \%$ and $25 \%$ of patients, respectively, at a dose of $10 \mathrm{mg}$ or $20 \mathrm{mg}$ in $89 \%$ and $11 \%$, respectively. Thus, the proportion of patients treated with CCBs increased from $52 \%$ to $89 \%$ at V2 (Figure 2), and the proportion of patients treated with ACE inhibitor decreased at V2. The proportion of patients treated with ARBs remained similar throughout the investigation. Additional changes in treatment regimens were recorded at FU1 and FU2 visits and titration on administered treatments were performed in $89 \%$ and $71 \%$ of patients at FU1 and FU2 visit. However, the average number of drugs per patient recorded at V1 $(2.7 \pm 1.3)$ remained rather similar at V2 $(3.0 \pm 1.1)$ and up to FU2 visit $(3.0 \pm$ $1.2)$.

\section{Efficacy}

Office BP was $147 \pm 16 \mathrm{mmHg} / 87 \pm 13 \mathrm{mmHg}$ (mean \pm SD) at baseline (V1). These values decreased significantly with the treatment adaptations and further during the use of TMS program to $134 \pm 15 / 80$ $\pm 9 \mathrm{mmHg}$ at FU2 resulting in significant reduction of $-10 \pm 21 \mathrm{mmHg}$ $(\mathrm{p}=0.028)$ and $-5 \pm 11 \mathrm{mmHg}(\mathrm{p}=0.049)$ (Figure 3$)$. No relevant change in mean HR was observed. At baseline visit, $28 \%$ of the patients were on a target $\mathrm{BP}<140 / 90 \mathrm{mmHg}$ and only $9 \%$ on a target of $<130 / 80$ mmHg according to ESH guidelines. At the FU2 visit, 56\% of patients achieved a target $\mathrm{BP}<140 / 90 \mathrm{mmHg}$ and $41 \%$ achieved the target of $<130 / 80 \mathrm{mmHg}$.

Home BP measured with the TMS was $134 \pm 32 / 78 \pm 19 \mathrm{mmHg}$ during the run-in phase; $126 \pm 41 / 73 \pm 24 \mathrm{mmHg}$ during the titration period and $129 \pm 32 / 73 \pm 19 \mathrm{mmHg}$ during the maintenance phase (Figure 3 ). Thus systolic and diastolic BP decreased respectively by -3 $\pm 1 \mathrm{mmHg}(\mathrm{p}=0.043)$ and $-3 \pm 1 \mathrm{mmHg}(\mathrm{p}=0.021)$ between the run-in period and the end of the maintenance phase (Figure 3 ). No significant change in heart rate and body weight was observed by means of home measurements. A significant increase in serum creatinine $(p=0.022)$ and significant decreases in Estimated Glomerular Filtration Rate
(eGFR) $(\mathrm{p}=0.047)$, and a trend for a decrease in creatinine clearance $(\mathrm{p}=0.051)$ were observed (Table 2$)$.

\section{Tolerability}

Adverse drug reactions to lercanidipine were assessed by a systematic check list at each visit, while all other Adverse Events (AEs) were recorded as spontaneously reported by the patients and analysed descriptively (without $t$-testing). The frequency of peripheral edema at baseline, i.e before the anticipated treatment modification, was $35 \%$ whereas the frequency of edema at FU2, i.e. after the introduction of

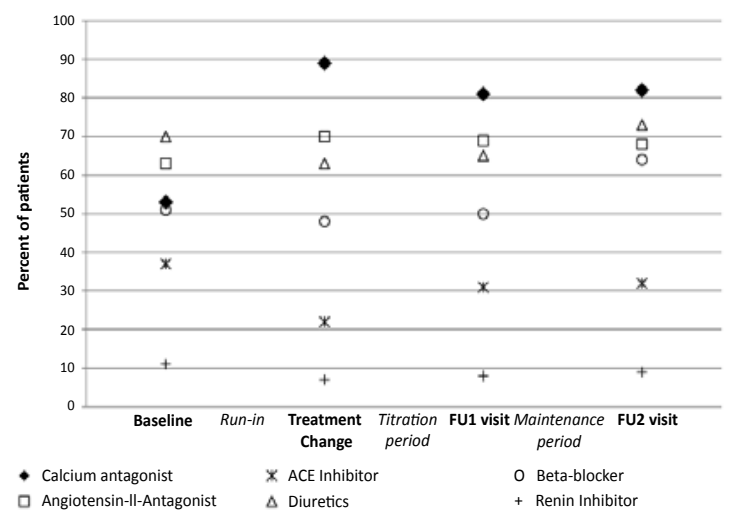

Figure 2: Proportion of patients treated with one or more of the 6 antihypertensive classes at baseline, visit of treatment change and follow-up visits (FU1 and FU2).

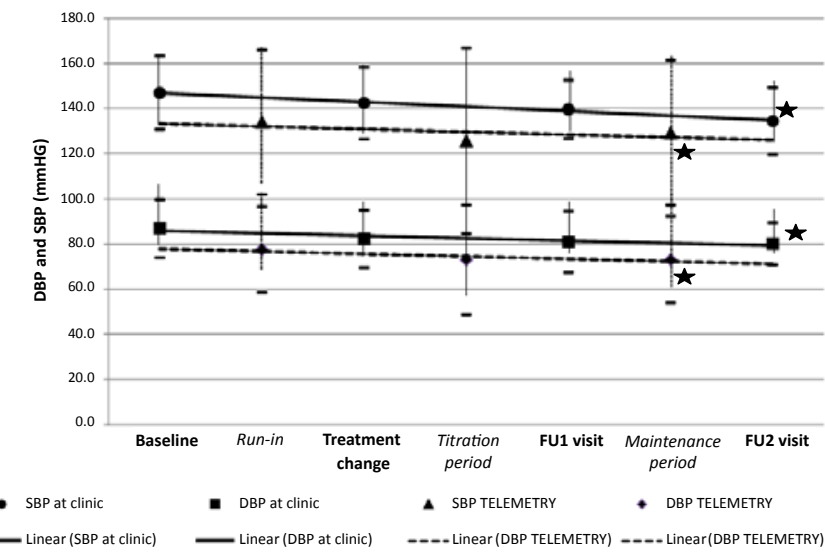

Asterisk represents statistically significant changes $(p<0.05)$ compared to V1 and run-in period, respectively.

Figure 3: SBP and DBP measured at clinic and at home using telemetry at baseline, at V2 (treatment change) and at follow-up visits (FU1 and FU2).

\begin{tabular}{|c|c|c|c|c|c|}
\hline & \multicolumn{2}{|c|}{ Baseline (V1) } & \multicolumn{2}{|c|}{ End of follow up (FU2) } & \multirow{2}{*}{$\begin{array}{c}p= \\
0.022\end{array}$} \\
\hline Serum creatinine & $202(95)$ & $\mathrm{Mmol} / \mathrm{L}$ & 252 (129) & $\mu \mathrm{mol} / \mathrm{L}$ & \\
\hline $\begin{array}{l}\text { Creatinine clear- } \\
\text { ance }\end{array}$ & $48(25)$ & $\mathrm{mL} / \mathrm{min}$ & $41(23)$ & $\mathrm{mL} / \mathrm{min}$ & 0.051 \\
\hline eGFR & $36(18)$ & $\mathrm{mL} / \mathrm{min} / 1.73 \mathrm{~m}^{2}$ & $31(17)$ & $\mathrm{mL} / \mathrm{min} / 1.73 \mathrm{~m}^{2}$ & 0.047 \\
\hline $\begin{array}{l}\text { Urine Albumine/ } \\
\text { creatinine }\end{array}$ & $66(110)$ & $\mathrm{mg} / \mathrm{mmol}$ & $22(29)$ & $\mathrm{mg} / \mathrm{mmol}$ & 0.383 \\
\hline $\begin{array}{l}\text { Urine Proteine/ } \\
\text { creatinine }\end{array}$ & $190(290)$ & $\mathrm{mg} / \mathrm{mmol}$ & $110(130)$ & $\mathrm{mg} / \mathrm{mmol}$ & 0.208 \\
\hline
\end{tabular}

Values are means +/- SD

Table 2: Laboratory values at baseline and at the end of the study. 
lercanidipine, was $33 \%$. The frequency of headache and flush showed a marked decrease from $29 \%$ and $14 \%$, respectively at baseline as compared to $16 \%$ and $6 \%$ at the last visit.

\section{Discussion}

The results of this pilot study indicate that the combined used of a TMS enabling to follow home BP together with the use of the calcium channel blocker lercanidipine may be useful to improve the treatment of hypertension in CKD patients with uncontrolled BP, with $40 \%$ of patients reaching the target BP during the study. Our study also shows that the use of the calcium channel blocker lercanidipine is well tolerated with no significant change in body weight under treatment and a significant reduction of the incidence of vasodilation-related side effects.

The control of hypertension remains low in the general population and particularly insufficient in hypertensive patients suffering from chronic nephropathies $[1,2]$. There is therefore a need for improvement and new therapeutic strategies have to be developed to improve the actual results in order to reduce the incidence of patients reaching end-stage renal disease. This pilot study suggests that the combined use of a TMS enabling physicians to follow continuously home BP and a well tolerated calcium channel blocker may be one way to improve $\mathrm{BP}$ control in $\mathrm{CKD}$ patients. Indeed, the conjunction of the two interventions resulted in significant decreases in both, clinic and home $\mathrm{BP}$ and achieving target $\mathrm{BP}$ values in a high proportion of the patients. The major limitation of this study is the design that does not enable to disentangle the respective role of the TMS and the administration of lercanidipine because both interventions were simultaneous. To answer this question a more complex study design and a much larger group of patients would have been necessary. Recent large controlled studies have actually demonstrated the benefits of a TMS in hypertension management particularly in patients with uncontrolled $\mathrm{BP}[7,8]$.

Nevertheless, our results provide some interesting information for practitioners. First, our results confirm that a continuous telemonitoring of home BP is feasible and well accepted by patients. Several previous studies have demonstrated the clinical benefits of measuring home BP using similar concepts in hypertension and heart failure $[7,8,18$ 20]. Continuous monitoring of home BP has been shown to improve BP control in part because it supports drug adherence and because it enables rapid medical interventions [6]. As shown in this study, it may also be useful for BP monitoring when the antihypertensive treatment regimen needs to be optimized. The ability to define alerts for high or low $\mathrm{BP}$ values may also help to improve the security and the tolerability of treatments. Figure 4 illustrates two cases of monitoring with the changes in BP.

The significant reductions of systolic and diastolic BP observed in our hypertensive patients with renal insufficiency $(-10 \pm 21 \mathrm{mmHg}$ and $-5 \pm 11 \mathrm{mmHg}$, respectively), were not as marked as compared to results of other clinical studies with lercanidipine [21-26]. However, one has to acknowledge that these patients were already heavily treated and with a long standing CKD and a reduced renal function. These patients are known to be more difficult to control. A subgroup analysis of a large observational study using lercanidipine also revealed smaller BP reductions in patients with diabetes as compared to the non-diabetics [26]. Thus, the fact that $56 \%$ and $41 \%$ of patients achieved target office BP levels of $<140 / 90 \mathrm{mmHg}$ and $<130 / 80 \mathrm{mmHg}$, respectively can be considered as remarkable considering the difficulty to normalize BP in this patient's subgroup.

As expected, BP measurements at home were consistently lower

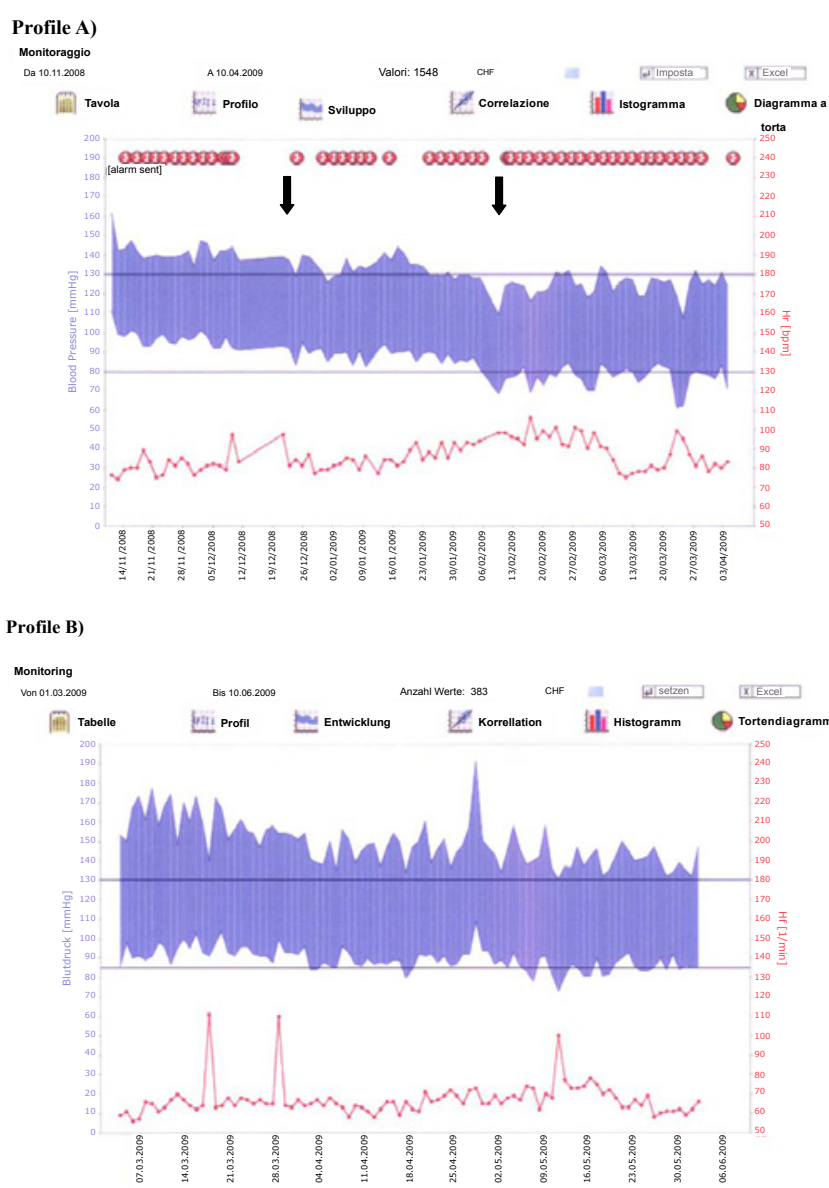

Figure 4: Representative profiles of two patients: A) Male patient, 61 years old B) Male patient, 77 years old. The arrows indicate the date of V2, when the anticipated modification of the treatment regimen was performed and V3. Profile between arrow 1 and 2 represents the FU1 period while the profile right to second arrow represents the period of FU2.

than those measured at the clinic and were to some extend within predefined target BP values although one has to remember that according to European guidelines home BP targets are lower than office targets [3]. Moreover, no prospective study has really defined the home BP targets in CKD patients [27]. Our observation also refers to the ongoing discussion on the accuracy of BP measurements during a visit in the clinic and on the clinical impact of the "white coat phenomenon". The benefits of home BP measurements have been reviewed recently [28]. Importantly, studies have shown that home BP correlates better with target organ damages and the risk of cardiovascular events than office BP [29,30]. However, the variations in home BP measurements were rather high. But, the relatively large number of measurements enables to calculate reliable means and standard deviations for weekly and/or monthly reports. The high variability of home BP measurements has two important clinical consequences: first, patients need to be instructed carefully on how to perform the measurements in standardized conditions (e.g. performing the measurements always at the same morning and evening time, as well as sitting for 3 minutes before recording), and second, when using a telemonitoring system physicians need to set the alerts at a larger range for a single observation 
and to define reasonable ranges for the last 3 to 5 measurements in order to avoid unnecessary interventions.

One objective of the study was to investigate the clinical benefits of using lercanidipine to lower BP in patients with CKD. Calcium channel blockers are very effective in the management of hypertension in CKD patients particularly in combination with a RAS blocker [3133]. However, the occurrence of peripheral edema is one of the major limitation of this antihypertensive class, although the incidence of edema is reduced when CCB are administered with RAS blockers. Lercanidipine is a third generation dihydropyridine with a high vascular selectivity [14]. Its use has been associated with a lower incidence of peripheral oedema when compared to nifedipine GITS in a randomized double-blind study [34]. In an open-label, switching from a first generation CCB to lercanidipine reduces the likelihood of developing peripheral edema by approximately $50 \%$ [25] and this was confirmed in a large observational prospective study published by Burnier et al [26]. The overall findings of randomized controlled trials revealed that lercanidipine is as effective in lowering blood pressure as other CCBs but with particular nephroprotective features and an improved tolerability when compared with the first and second generations of CCBs. In a randomized, double-blind study in patients with type 2 diabetes, persistent microalbuminuria and potential risk for diabetic nephropathy, lercanidipine, was as effective as ramipril in lowering $\mathrm{BP}$ and urinary albumin excretion [35]. Therefore lercanidipine may be an effective choice for the treatment of hypertension in CKD patients.

The present data tend to confirm the antihypertensive efficacy of lercanidipine in $\mathrm{CKD}$ patients. Although the individual treatment regimens were changed in all included patients to achieve the target BP, it is important to point out that the average number of drugs per patient remained similar as of the first visit to the last visit indicating that the changes in BP are due essentially to the introduction of lercanidipine and of the TMS and not to the addition of other antihypertensive agents. However, this is not a controlled study and one cannot exclude that the adherence to other prescribed treatments has also improved during the monitoring leading to a better BP control. Another marker of the improved $\mathrm{BP}$ control is the increase in serum creatinine and decrease in eGFR. These changes very likely reflect the acute renal hemodynamic adaptations to the decrease in BP. A similar phenomenon has been described in large clinical trials implying the administration of CCB to CKD patients [33].

One issue in CKD patients is the incidence of peripheral edema. Edema is common in these patients because of the renal disease itself and are markedly aggravated by the prescription of CCB. In our study, $35 \%$ of patients had edema at baseline. In order to assess the changes in edema induced by lercanidipine we monitored body weight by telemonitoring. No change in body weight was observed upon introduction of lercanidipine and the clinical incidence of peripheral edema decreased marginally by $2 \%$. Thus, the reduction on the incidence of edema in this study was not as marked as observed in other studies in non CKD patients $[25,26]$. Once again, this may reflect the impact of the background renal disease. Nevertheless we observed a significant reduction of other side effects including headache and flush. A similar finding has been reported in a cross-over study when patients were switched from another CCB to lercanidipine [25].

In conclusion, the results of this pilot study suggest that a telemonitoring system enabling to follow home BP may be useful to improve BP control in hypertensive patients with CKD. However, a prospective randomized control study would be needed to assess the real added benefits of this strategy. Administration of lercanidipine in CKD patients was effective and well tolerated.

\section{Acknowledgement}

This observational study was supported by a grant of Robapharm AG. The TMS consisted of commercially available device of I.E.M. GmbH. The EDC system used for this study was provided by clinIT AG, Freiburg, Germany, and the statistical analysis was performed by the Dr. M. Köhler GmbH, Freiburg, Germany.

\section{References}

1. Bakris G, Vassalotti J, Ritz E, Wanner C, Stergiou G, et al. (2010) CKD Consensus Working Group. National Kidney Foundation consensus conference on cardiovascular and kidney diseases and diabetes risk: an integrated therapeutic approach to reduce events. Kidney International 78: 726-36.

2. Muntner P, Anderson A, Charleston J, Chen Z, Ford V, et al. (2010) Chronic Renal Insufficiency Cohort (CRIC) Study Investigators. Hypertension awareness, treatment, and control in adults with CKD: results from the Chronic Renal Insufficiency Cohort (CRIC) Study. Am J Kidney Dis 55: 441-51.

3. Zanchetti A (2003) 2003 European Society of Hypertension: European Society of Cardiology guidelines for the management of arterial hypertension. Lippincott Williams \& Wilkins Ltd 21: 1011-1053.

4. Wolf-Maier K, Cooper RS, Kramer H, Banegas JR, Giampaoli S, et al. (2004) Hypertension treatment and control in five European countries, Canada, and the United States. Hypertension 43: 10-17.

5. Burnier M (2006) Medication adherence and persistence as the cornerstone of effective antihypertensive therapy. Am J Hypertens 19: 1190-6

6. Agarwal R, Bills JE, Hecht TJ, Light RP (2011) Role of home blood pressure monitoring in overcoming therapeutic inertia and improving hypertension control: a systematic review and meta-analysis. Hypertension. 57: 29-38.

7. Green BB, Cook AJ, Ralston JD, Fishman PA, Catz SL, et al. (2008) Effectiveness of home blood pressure monitoring, Web communication, and pharmacist care on hypertension control: a randomized controlled trial. JAMA 299: 2857-67.

8. Bosworth HB, Powers BJ, Olsen MK, McCant F, Grubber J, et al. (2011) Home blood pressure management and improved blood pressure control: results from a randomized controlled trial. Arch Intern Med 171: 1173-80.

9. Burnier M, Hess B, Greminger P, Waeber B (2005) Determinants of persistence in hypertensive patients treated with irbesartan: results of a postmarketing survey. BMC Cardiovasc Disord 5: 13

10. Julius S, Kjeldsen SE, Weber M, Brunner HR, Ekman S, et al. (2004) Outcomes in hypertensive patients at high cardiovascular risk treated with regimens based on valsartan or amlodipine: the VALUE randomized trial. The Lancet 363: 2022-2031

11. Wright JT Jr, Dunn JK, Cutler JA, Davis BR, Cushman WC, et al. (2005) ALLHAT Collaborative Research Group. Outcomes in hypertensive black and nonblack patients treated with chlorthalidone, amlodipine, and lisinopril. JAMA 293: $1595-160$

12. Staessen JA, Fagard R, Thijs L, Celis H, Arabidze GG, et al. (1997) Randomised double-blind comparison of placebo and active treatment for older patients with isolated systolic hypertension. The Systolic Hypertension in Europe (Syst-Eur) Trial Investigators. The Lancet 350: 757-764.

13. Poulter NR, Wedel H, Dahlof B, Sever PS, Beevers DG, et al. (2005) Role of blood pressure and other variables in the differential cardiovascular event rates noted in the Anglo-Scandinavian Cardiac Outcomes Trial-Blood Pressure lowering Arm (ASCOT-BPLA). The Lancet 366: 907-913.

14. Meredith PA (1999) Lercanidipine: A novel lipophilic dihydropyridin calcium antagonist with long duration of action and high vascular selectivity. Exp Opin Invest Drugs 8: 1043-62.

15. Sabbatini M, Leonardi A, Testa R, Vitaioil L, Amenta F (2000) Effect of calcium antagonists on glomerular arterioles in spontaneously hypertensive rats. Hypertension 35: 775-79.

16. Robles NR, Ocon J, Gomez C, M Manjon, L Pastor, et al. (2005) Lercanidipine in patients with chronic renal failure: the ZAFRA study. Ren Fail 27: 73-80.

17. TH Westhoff, S Schmidt, W Zidek, van der Giet M (2007) Validation of the Stabil-O-Graph blood pressure self-measurement device. J Hum Hypertens22: 233-235 
Citation: Burnier M, Bock A, Halabi G, Gasser UE, Bertschi PA, et al. (2012) Usefulness of Telemetric Blood Pressure Monitoring in Hypertensive Patients with Chronic Kidney Diseases. J Nephrol Therapeut 2:122. doi:10.4172/2161-0959.1000122

Page 6 of 6

18. Kielblock B, Frye Ch, Kottmair S, Hudler Th, Siegmund-Schultze E, et al. (2007) Impact of telemetric management on overall treatment costs and mortality rate among patients with chronic heart failure. Dtsch Med Wochenschr 132: 417422

19. Scherr D, Kastner P, Kollmann A, Hallas A, Auer J, et al. (2009) Effect of home-based telemonitoring using mobile phone technology on the outcome of heart failure patients after an episode of acute decompensation: randomized controlled trial. J Med Internet Res. 11: e34.

20. Takahashi PY, Hanson GJ, Pecina JL, Stroebel RJ, Chaudhry R, et al. (2010) A randomized controlled trial of telemonitoring in older adults with multiple chronic conditions: the Tele-ERA study. BMC Health Serv Res 10: 255.

21. Leonetti G, Magnani B, Pessina AC, Rappelli A, Trimarco B, et al. (2002) Tolerability of Long-Term Treatment With Lercanidipine Versus Amlodipine and Lacidipine in Elderly Hypertensive. Am J Hypertens 15: 932-940

22. Cherubini A, Fabris F, Ferrari E, Domenico C, Senin U, et al. (2003) Comparative effects of lercanidipine, lacidipine and nifedipine gastrointestinal therapeutic system on blood pressure and heart rate in elderly hypertensive patients: the Elderly and Lercanidipine (ELLE) study. Arch Gerentol Geriatr 37: 203-212.

23. Barrios V, Navarro A, Esteres A, Luque M, Joaquima R, et al. (2002) Antihypertensive Efficacy and Tolerability of Lercanidipine in Daily Clinical Practice. The ELYPSE Study, Blood Pressure 11: 95-100.

24. DeGiorgio LA, Orlandini F, Malasoma P, Zappa A (1999) Double-blind, crossover study of lercanidipine versus amlodipine in the treatment of mild to moderate essential hypertension. Curr Ther Research 60: 511-520

25. Borghi C, Prandin MG, Dormi A, Ambrosioni E (2003) Study Group of the Regional Unit of the Italian Society of Hypertension. Improved tolerability of the dihydropyridine calcium-channel antagonist lercanidipine: the lercanidipine challenge trial. Blood Press Suppl 1: 14-21

26. Burnier M, Gasser UE (2007) Efficacy and tolerability of lercanidipine in with hypertension:Results of a phase IV study in general practice. Expert Opin Pharmacother 8: 2215-2223
27. Agarwal R (2011) Blood pressure goal in chronic kidney disease: what is the evidence? Curr Opin Nephrol Hypertens 20: 229-232

28. Stergiou GS, Bliziotis IA (2011) Home blood pressure monitoring in the diagnosis and treatment of hypertension: a systematic review. Am J Hypertens. 24: 123-34.

29. Fagard RH, Van Den Broeke C, De Cort P (2005) Prognostic significance of blood pressure measured in the office, at home and during ambulatory monitoring in older patients in general practice. J Hum Hypertens. 19: 801-807.

30. Niiranen TJ, Hänninen MR, Johansson J, Reunanen A, Jula AM (2010) Homemeasured blood pressure is a stronger predictor of cardiovascular risk than office blood pressure: the Finn-Home study. Hypertension. 55: 1346-51.

31. Rahman M, Pressel S, Davis BR, Nwachuku C, Wright JT Jr, et al. (2005) Renal outcomes in high-risk hypertensive patients treated with an angiotensinconverting enzyme inhibitor or a calcium channel blocker vs a diuretic: a report from the Antihypertensive and Lipid-Lowering Treatment to Prevent Heart Attack Trial (ALLHAT). Arch Intern Med 165: 936-46

32. Segura J, García-Donaire JA, Ruilope LM (2005) Calcium channel blockers and renal protection: insights from the latest clinical trials. J Am Soc Nephro 1: S64-66.

33. Bakris GL, Sarafidis PA, Weir MR, Dahlöf B, Pitt B, et al. (2010) ACCOMPLISH Trial investigators. Renal outcomes with different fixed-dose combination therapies in patients with hypertension at high risk for cardiovascular events (ACCOMPLISH): a prespecified secondary analysis of a randomised controlled trial.The Lancet 375: 1173-1181.

34. Fogari R, Malamani GD, Zoppi A, Fogari E, Mugellini A, et al. (2000) Comparative Effect of Lercanidipine and Nifedipine Gastrointestinal Therapeutic System on Ankle Volume and Subcutaneous Interstitial Pressure in Hypertensive Patients: A Double-Blind, randomized, Parallel-Group Study. Curr Ther Res 61: 850-861.

35. Vestra MD, Pozza G, Mosca A, Grazioli V, Lapolla A, et al. (2004) Effect of lercanidipine compared with ramipril on albumin excretion rate in hypertensive Type 2 diabetic patients with microalbuminuria: DIAL study. Diabetes Nutr Metab 17: 259-266. 